\title{
Understanding of Ultrasonic Assisted Machining with Diamond Grinding Tool
}

\author{
Kyung-Hee Park' ${ }^{1}$, Yun-Hyuck Hong ${ }^{2}$, Kyeong-Tae Kim³ ${ }^{3}$, Seok-Woo Lee ${ }^{3}$, \\ Hon-Zong Choi ${ }^{2}$, Young-Jae Choi ${ }^{2}$ \\ ${ }^{1}$ Korea Institute on Industrial Technology, Future Manufacturing System R\&D Group, \\ Manufacturing System R\&D Department, Cheonan-si, South Korea \\ ${ }^{2}$ Korea Institute on Industrial Technology, IT Converged Process R\&D Group, \\ Convergent Technology R\&D Department, Ansan-si, South Korea \\ ${ }^{3}$ Korea Institute on Industrial Technology, Chungcheong Regional Division, Cheonan-si, South Korea \\ Email: kpark@kitech.re.kr, secar@kitech.re.kr, kimkt@kitech.re.kr, swlee@kitech.re.kr, \\ choihz@kitech.re.kr, youngjae@kitech.re.kr
}

Received November 8, 2013; revised December 11, 2013; accepted December 23, 2013

Copyright (c) 2014 Kyung-Hee Park et al. This is an open access article distributed under the Creative Commons Attribution License, which permits unrestricted use, distribution, and reproduction in any medium, provided the original work is properly cited. In accordance of the Creative Commons Attribution License all Copyrights (C) 2014 are reserved for SCIRP and the owner of the intellectual property Kyung-Hee Park et al. All Copyright @ 2014 are guarded by law and by SCIRP as a guardian.

\section{ABSTRACT}

In this work, machining test was carried out in various machining conditions using ultrasonic vibration capable CNC machine. For work material, alumina ceramic $\left(\mathrm{Al}_{2} \mathrm{O}_{3}\right)$ was used while for tool material diamond electroplated grinding wheel was used. To evaluate ultrasonic vibration effect, grinding test was performed with and without ultrasonic vibration in same machining condition. In ultrasonic mode, ultrasonic vibration of $20 \mathrm{kHz}$ was generated by HSK 63 ultrasonic actuator. On the other hand, grinding forces were measured by KISTLER dynamometer. And an optimal sampling rate for grinding force measurement was obtained by a signal processing and frequency analysis. The surface roughness of the ceramic was also measured by using stylus type surface roughness instrument and atomic force microscope (AFM). Besides, the scanning electron microscope (SEM) was used for observation of surface integrality.

\section{KEYWORDS}

Ultrasonic Vibration; Grinding; Alumina Ceramic; Grinding Forces; Surface Roughness

\section{Introduction}

Ceramics have been considered as one of the important materials in engineering application due to its outstanding physical and mechanical properties such as high melting temperature, high wear resistant, etc. [1-3]. However, there are some difficulties in machining of the ceramic materials owing to its hard and brittle nature on top of bad uniformity and low reliability, so the ceramics are classified into hard-to-cut materials [4,5]. For this reason, ultrasonic assisted machining, which is a hybrid process that combines the material removal mechanism and ultrasonic vibration, has been considered. This process can be useful for ceramic machining because an additional axial ultrasonic vibration can lead to reduction in cutting temperature and tool wear while maintaining high sur- face quality, which cannot be obtained from conventional machining [6-10]. Therefore, ultrasonic assisted machining has been applied for machining of the ceramics as an alternative method to traditional machining [9]. Several studies have been performed for machining of hard and brittle materials using ultrasonic vibration, which applied to either work material or a cutting spindle [2,6,7]. From the literature, it was found that better surface roughness and fracture strength were obtained. In addition, the cutting forces and tool wear were also reduced with applying ultrasonic vibration. On the other hand, in ultra-precision micromachining of brittle materials, elliptical vibration was capable of ductile machining without a brittle mode [11]. And Zhao et al. discussed theoretical critical grinding depth based on the ductile removal mechanisms of ultrasonic vibration grinding for the ceram- 
ics $[5,12,13]$.

This paper studied the ultrasonic vibration effect of diamond grinding tool on the ceramic machining. To evaluate the ultrasonic vibration effect, machining test was performed with and without the ultrasonic vibration. Finally, machining performance, such as grinding forces and surface roughness, was compared. Before the machining experiment, an optimal sampling rate of grinding force measurement was identified. The grinding forces were measured by KISTLER dynamometer while the surface roughness was measured by stylus type surface roughness instrument and atomic force microscope (AFM). In addition, the surface image of the ceramic was obtained by using scanning electron microscope (SEM).

\section{Experimental Method}

The experiment was performed on a CNC machine, which enables to generating ultrasonic vibration. Figure 1 shows a schematic of the machining experiment. The machining started at one corner of ceramic block while measuring grinding forces by KISTLER dynamometer (Type 9256C). After the machining, surface roughness of the ceramic was measured using stylus type surface roughness instrument (CS 3100S4 by Mitutoyo Co.) and AFM.

Diamond grinding tools with a diameter of $8 \mathrm{~mm}$, where the diamond grains were electroplated on the stainless tool with nickel matrix, was used. For the work material, alumina ceramic $\left(\mathrm{Al}_{2} \mathrm{O}_{3} \sim 96 \%\right)$ was used. To evaluate the ultrasonic vibration effect, conventional machining and ultrasonic assisted machining were performed. For the ultrasonic vibration in a longitudinal direction, a frequency of $20 \mathrm{kHz}$ generated by the HSK 63 type of ultrasonic actuator was used. The machining conditions are summarized in Table 1.

In addition, amplitude of ultrasonic grinding tool was measured by laser vibrometer (Polytec OFV-3001) and oscilloscope (Tektronix TDS1000B). The average amplitude was $4.5 \mu \mathrm{m}$ as shown in Figure 2.

\section{Measurement}

The grinding forces were measured by the dynamometer

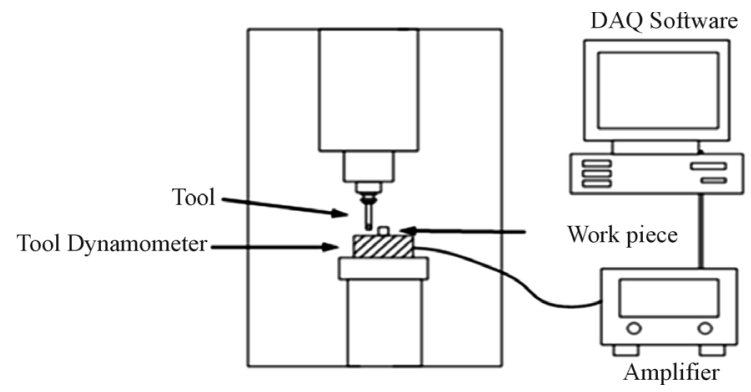

Figure 1. Schematic of experimental setup. and then the raw force data obtained was processed through a simple signal processing using commercially available software such as MATLAB and Dasylab. First, to identify an optimal sampling frequency in grinding process, the signal processing and frequency analysis were carried out by testing the sampling frequencies of 1 $\mathrm{kHz}, 10 \mathrm{kHz}$ and $20 \mathrm{kHz}$. Figure 3 shows the grinding force measurement at the sampling frequencies at each time domain obtained by MATLAB software. Figure 3(a) represents the grinding force in $y$-axis at the sampling rate of $1 \mathrm{kHz}$. It was observed that the force signals at the sampling rate of $1 \mathrm{kHz}$ were severely drifted and distorted compared to at those of $10 \mathrm{kHz}$ and $20 \mathrm{kH}$ as seen in Figures 3(b) and (c). Therefore, it can be said that the

Table 1. The machining conditions.

\begin{tabular}{cc}
\hline Workpiece material & $\begin{array}{c}\text { Alumina } \\
(96 \%, 20 \times 10 \times 10 \mathrm{~mm})\end{array}$ \\
\hline Cutter & $\varnothing 8$ \\
Machining speed $(\mathrm{m} / \mathrm{s})$ & $1.67,3.35$ \\
Coolant & Dry \\
Feedrate $(\mathrm{mm} / \mathrm{min})$ & 300,500 \\
Depth of cut $(\mathrm{mm})$ & 0.05 (radial), 2 (axial) \\
Diamond size $(\mu \mathrm{m})$ & D76 (FEPA standard) \\
Ultrasonic Vibration frequency $(\mathrm{kHz})$ & 20 \\
Amplitude $(\mu \mathrm{m})$ & 4.5 \\
\hline
\end{tabular}

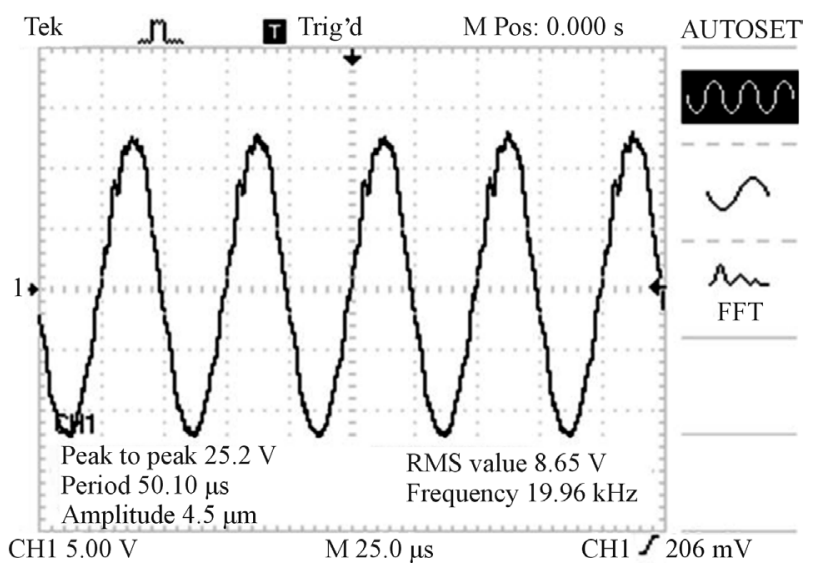

Figure 2. Amplitude of ultrasonic vibration.

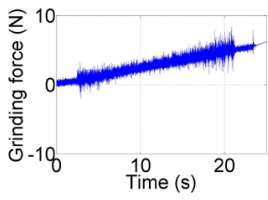

(a)

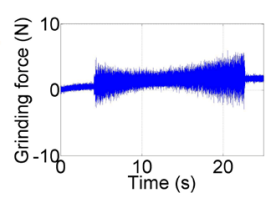

(b)

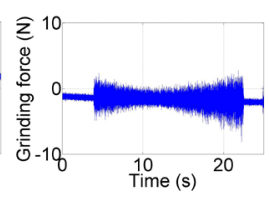

(c)
Figure 3. Grinding forces in y-axis at various sampling frequencies. (a) 1 kHz; (b) 10 kHz; (c) 20 kHz. 
sampling frequency beyond $10 \mathrm{kHz}$ should be used for reliable data in this work.

In addition, the force signals at sampling frequencies of $1 \mathrm{kHz}$ and $10 \mathrm{kHz}$ were compared by 3-D waterfall FFT analysis using MATLAB as in Figure 4. Figure 4(a) shows the FFT analysis for $1 \mathrm{kHz}$ and the frequency peaks observed was not clearly identified due to noise and signal distortion. However, for the case of $10 \mathrm{kHz}$ the peaks were distinguishable. For example, $133 \mathrm{~Hz}$ and $2.4 \mathrm{kHz}$ were found to be the frequencies of machining spindle and machine jig. On the other hand, a maximum frequency band width was only up to $500 \mathrm{~Hz}$ for $1 \mathrm{kHz}$ while it was up to $5 \mathrm{kHz}$ for $10 \mathrm{kHz}$. In these regards, the sample frequency of $10 \mathrm{kHz}$ was finally selected for the grinding force measurement.

Figure 5 shows the grinding forces measured at each direction. To obtain the grinding forces, there are several steps as depicted in Figure 6. Using Dasylab, first, drifts of the force signal in raw data was eliminated by a highpass filtering and then the maximum values were calculated from absolute values of the filtered signals, which were considered as the grinding forces.

A stylus type surface roughness instrument (Model: CS 3100S4-Mitutoyo Co.) was used for surface rough-

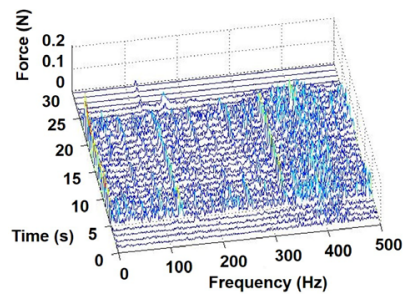

(a)

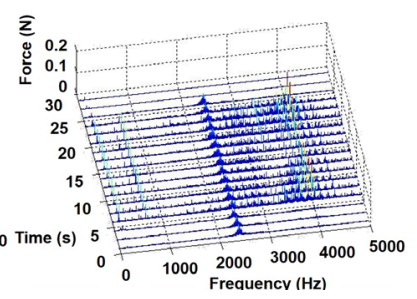

(b)
Figure 4. 3-D waterfall FFT at the sampling rate of $1 \mathbf{~ k H z}$ and $10 \mathrm{kHz}$. (a) $1 \mathrm{kHz}$ (X-axis); (b) $10 \mathrm{kHz}$ (X-axis). ness measurement. For evaluating the surface integrity of the work material, SEM equipment (Model: Hitachi S4300) and AFM were used.

\section{Results and Discussions}

Figure 7 exhibits comparison of the grinding forces at various grinding conditions. Overall, the grinding forces in ultrasonic assisted grinding were slightly reduced compared to the conventional grinding. However, in some cases, the grinding forces in ultrasonic case showed higher forces, especially for $\mathrm{y}$-axis components. This could be mainly because cutting depth in the ultrasonic grinding was deeper than that in the conventional grinding. As shown in Figure 8, groove depths generated by diamond grain in both the ultrasonic and conventional grinding were about $2.5 \mu \mathrm{m}$ and $3.2 \mu \mathrm{m}$ respectively. This difference might cause higher grinding forces in $\mathrm{y}$
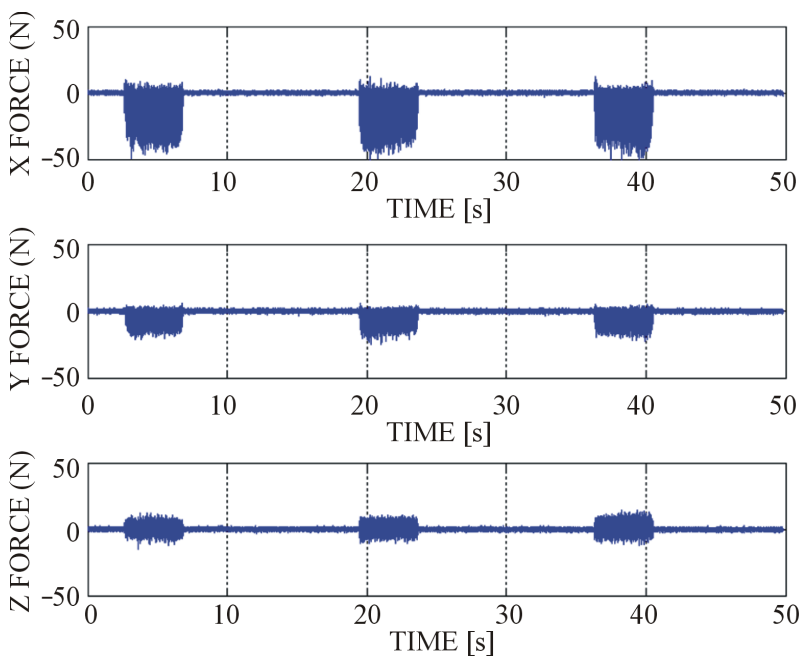

Figure 5. Grinding forces at each direction.

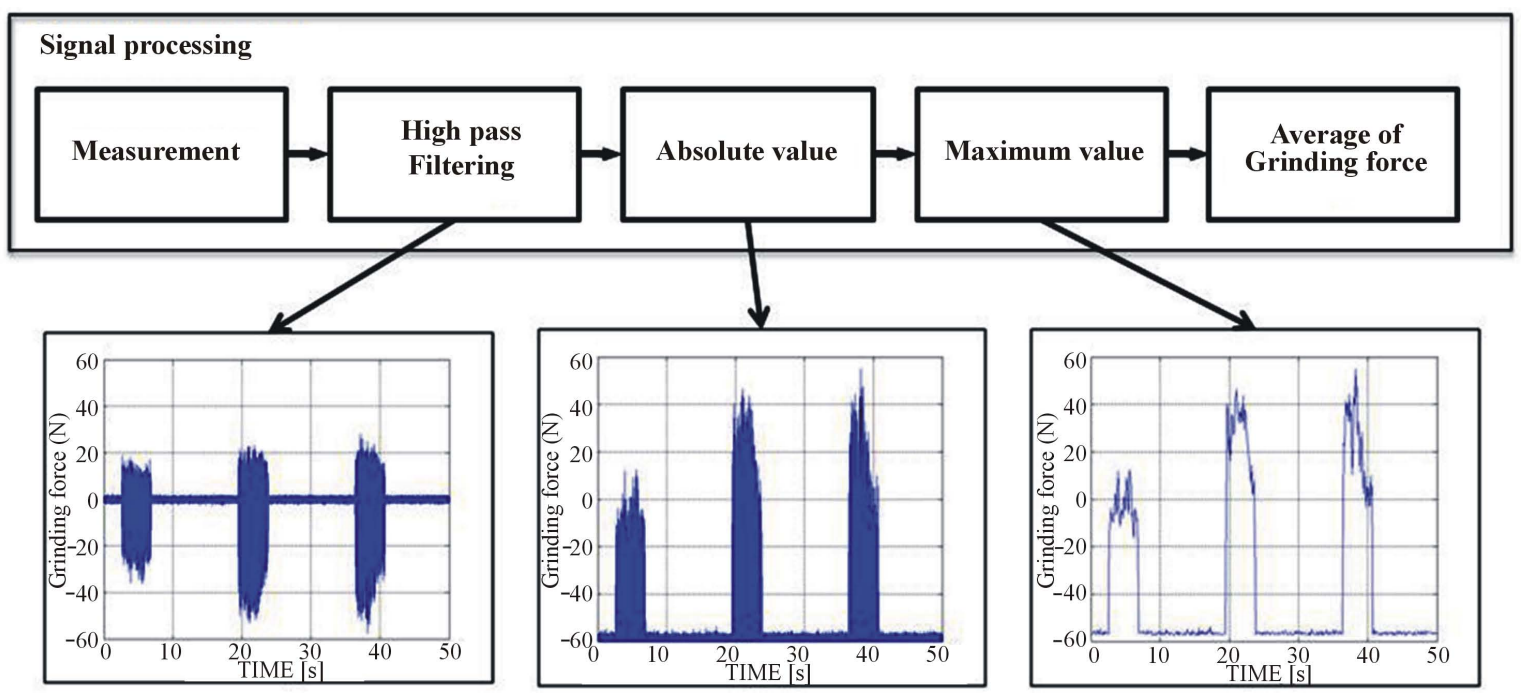

Figure 6. Grinding force signal processing procedures. 


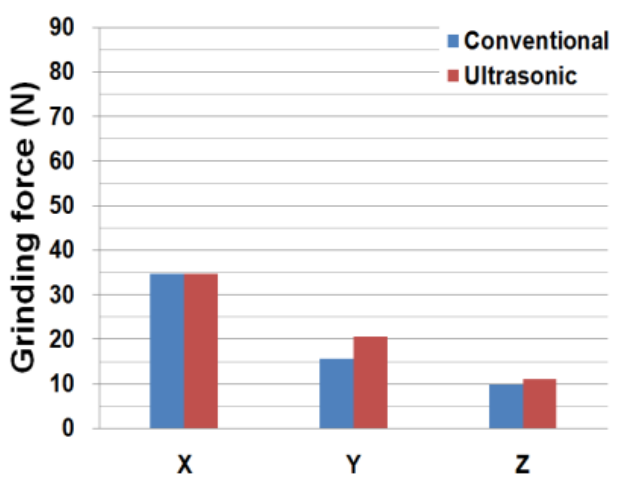

(a)

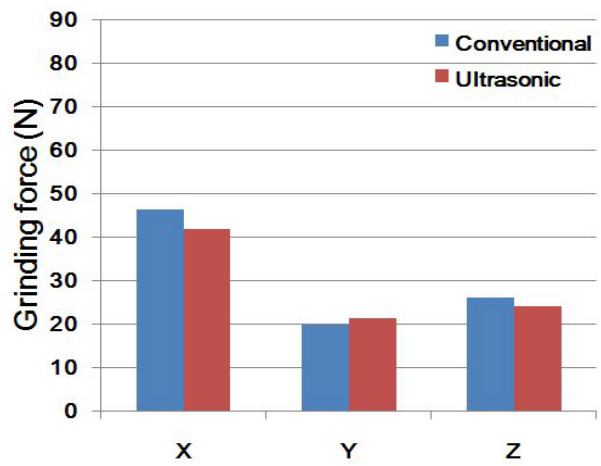

(c)

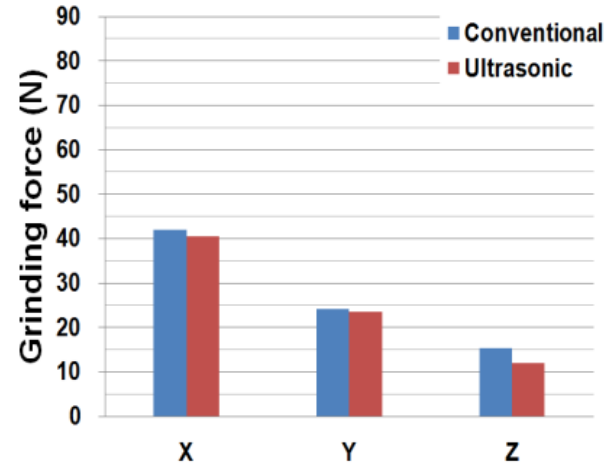

(b)

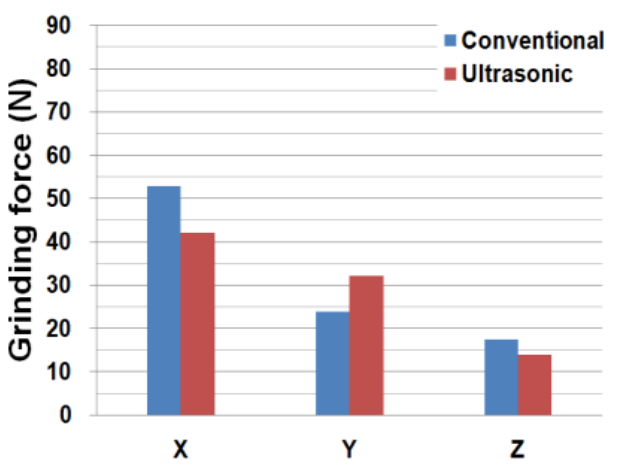

(d)

Figure 7. Analysis data of grinding forces. (a) $f=300 \mathrm{~mm} / \mathrm{min}, \mathrm{v}=1.67 \mathrm{~m} / \mathrm{s} ;(\mathrm{b}) \mathrm{f}=300 \mathrm{~mm} / \mathrm{min}, \mathrm{v}=3.35 \mathrm{~m} / \mathrm{s} ;(\mathrm{c}) \mathrm{f}=500 \mathrm{~mm} /$ $\min , v=1.67 \mathrm{~m} / \mathrm{s}$; (d) $f=500 \mathrm{~mm} / \mathrm{min}, \mathrm{v}=3.35 \mathrm{~m} / \mathrm{s}$.
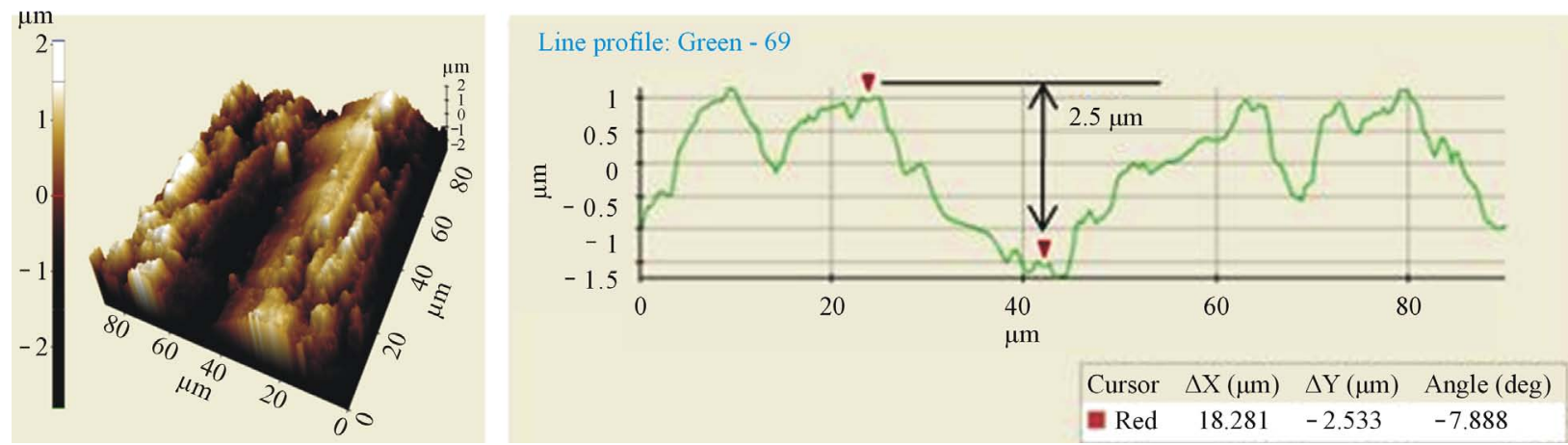

(a)
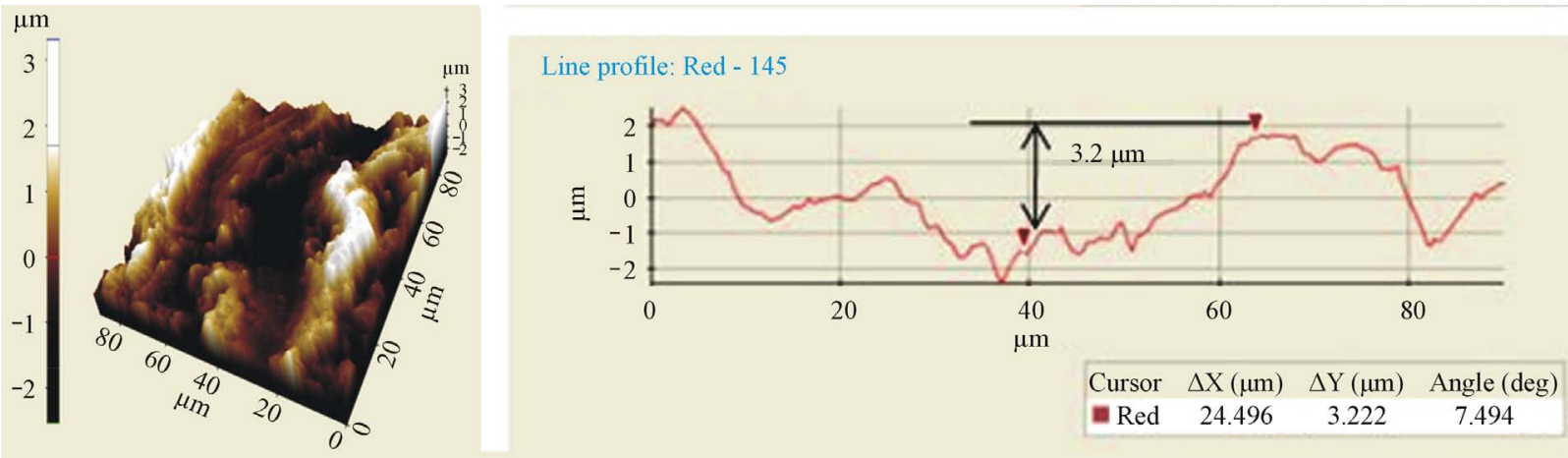

(b)

Figure 8. AFM images with 2D cross-sectional profiles. (a) Conventional grinding; (b) Ultrasonic grinding. 
direction. Another possible scenario could be that a grinding length of the ultrasonic grinding for a single diamond grain at one contact time, $\Delta \mathrm{t}$, is much larger than that of the conventional grinding as seen in Figure 9. This might increase the grinding force slightly. In addition, it was also found that the grinding force increased with grinding wheel speed and feed rate increased.

Surface roughness was measured by stylus type measurment equipment in terms of the grinding speed and the feed rate. As shown in Figure 10, the ultrasonic grinding shows better surface roughness about $4 \%$ - 15\% than the conventional grinding. And also it was observed that surface roughness improved as the feed rate decreased and the grinding speed increased.

Figure 11 shows SEM images of machined surface of the ceramic at various grinding conditions. Figure 11(a)

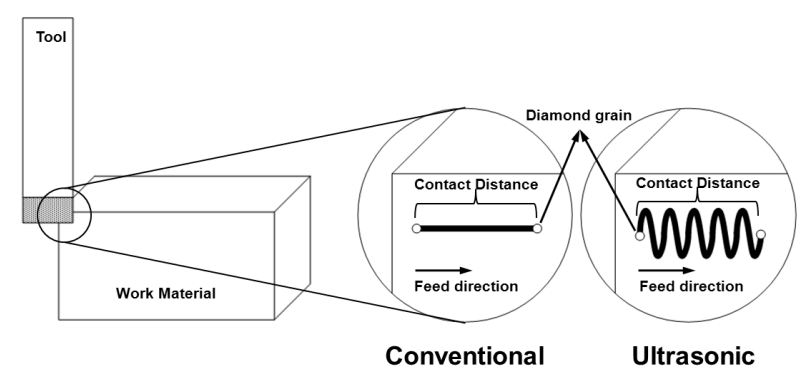

Figure 9. Kinematics of a diamond grain in conventional and ultrasonic grinding at a contact time, $\Delta \mathrm{t}$.
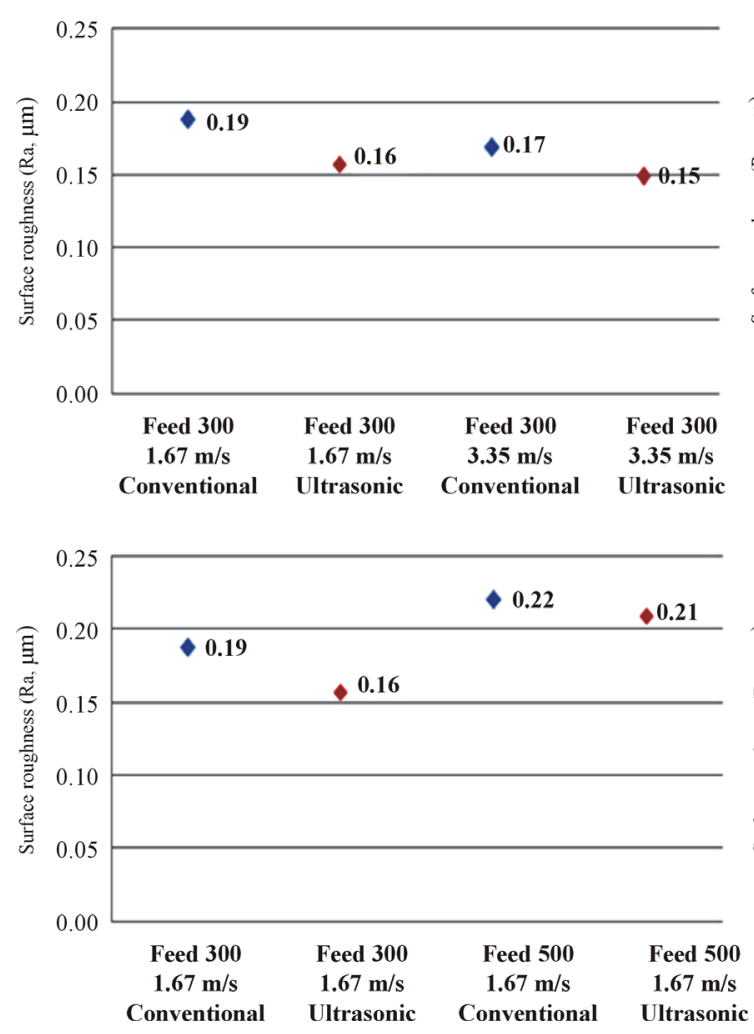

and (b) depicts the surface images at low grinding speed ( $v=1.67 \mathrm{~m} / \mathrm{s}$ ). In Figure 11(a), straight scoring marks of diamond grains were clearly observed in the conventional grinding while, in Figure 11(b), the sinusoidal paths of the grains were identified in the ultrasonic grinding. Actually the scoring marks showed $85 \mu \mathrm{m}$ period of a sine wave (Figure 11(b)), which was about to be same as kinematic calculation $(83.7 \mu \mathrm{m})$ as seen in Figure 12. In addition, width of the scoring marks was larger in ultrasonic grinding $(30 \mu \mathrm{m})$ than in conventional grinding $(21$ $\mu \mathrm{m}$ ) (See Figure 8). This means that one diamond can cover more surface area in the ultrasonic grinding, which shows that the ultrasonic vibration can grind the surface effectively. Figures 11(c) and (d) show the surface images at high grinding speed $(\mathrm{v}=3.35 \mathrm{~m} / \mathrm{s})$. For both cases, the scoring marks were not clearly formed as that at low grinding speed. This might be because the more diamond grains were involved for grinding action at a unit grinding distance, $\Delta \mathrm{d}$, due to high wheel speed. This is why the high wheel speed can enhance the surface integrity.

\section{Conclusions}

In this study, the conventional and ultrasonic assisted machining for the alumina ceramic was performed by using the diamond grinding wheel. The ultrasonic vibration effect was evaluated in terms of the grinding force and
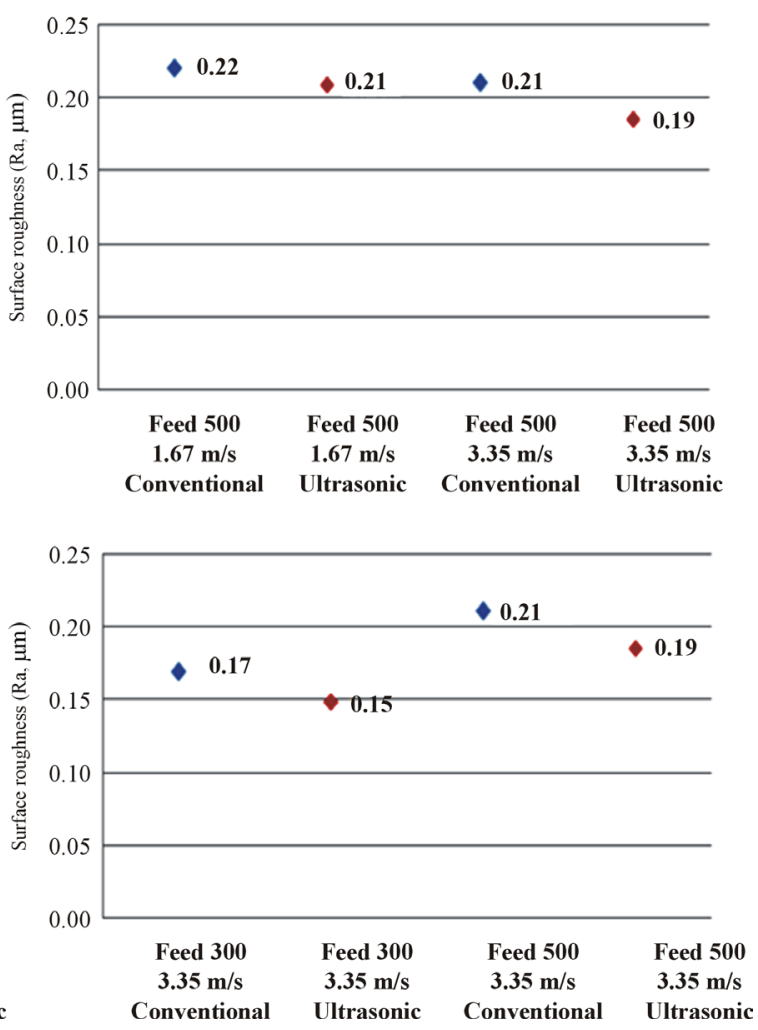

Figure 10. Surface roughness, Ra. 


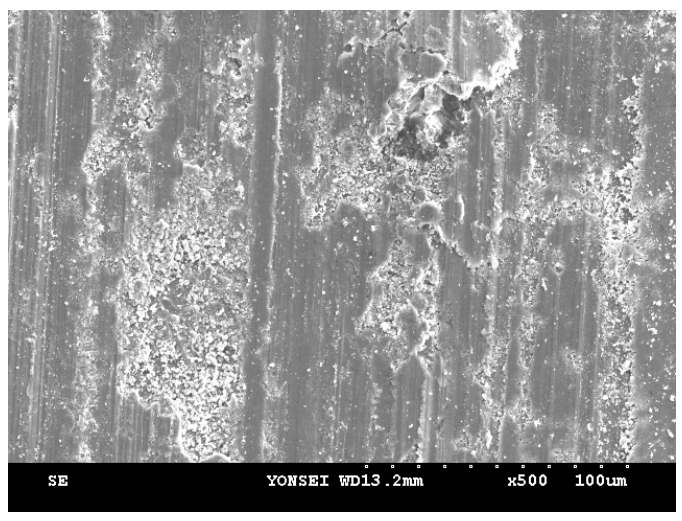

(a)

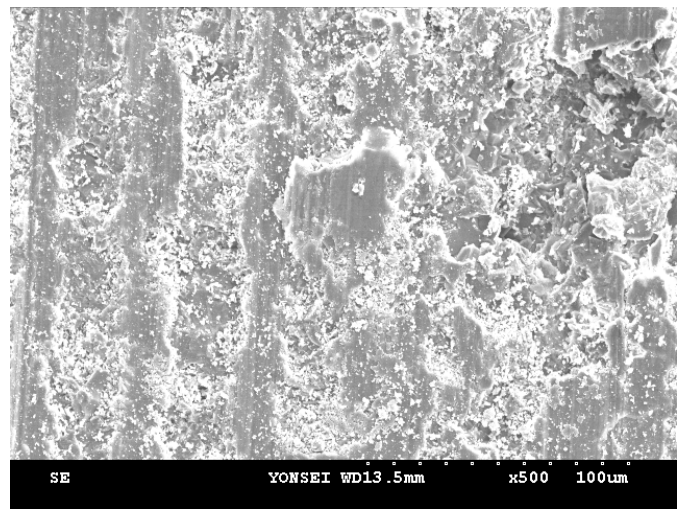

(c)

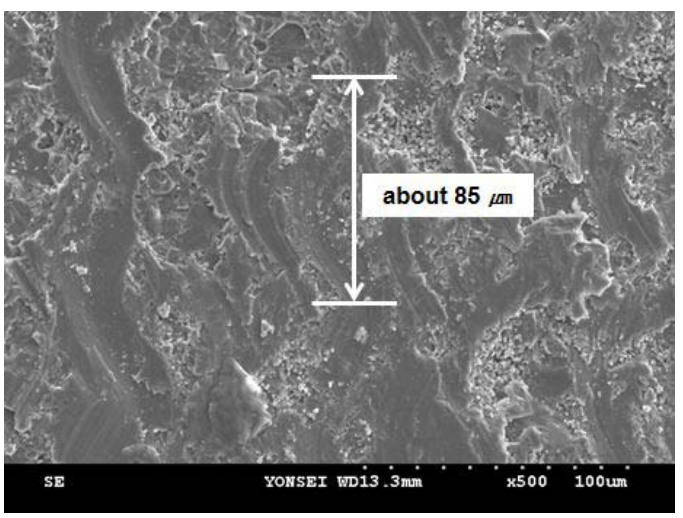

(b)

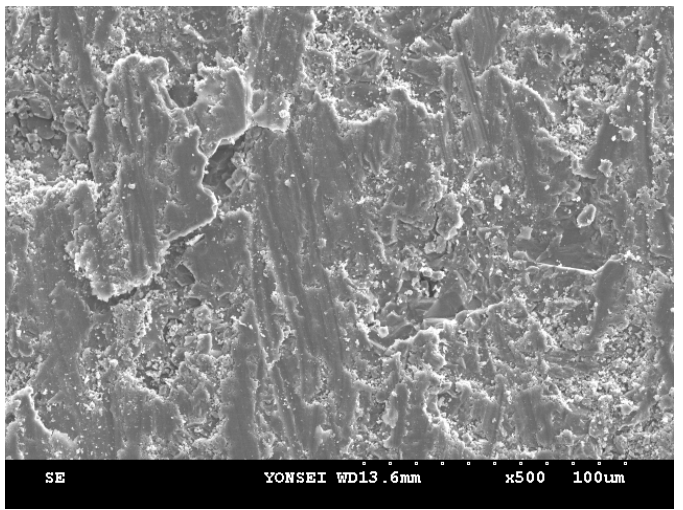

(d)

Figure 11. Surface image by SEM at $\mathrm{f}=500 \mathrm{~mm} / \mathrm{min}$. (a) $\mathrm{v}=1.67 \mathrm{~m} / \mathrm{s}$ (Conventional); (b) $\mathrm{v}=1.67 \mathrm{~m} / \mathrm{s}$ (Ultrasonic); (c) $\mathrm{v}=$ $3.35 \mathrm{~m} / \mathrm{s}$ (Conventional); (d) $\mathrm{v}=3.35 \mathrm{~m} / \mathrm{s}$ (Ultrasonic).

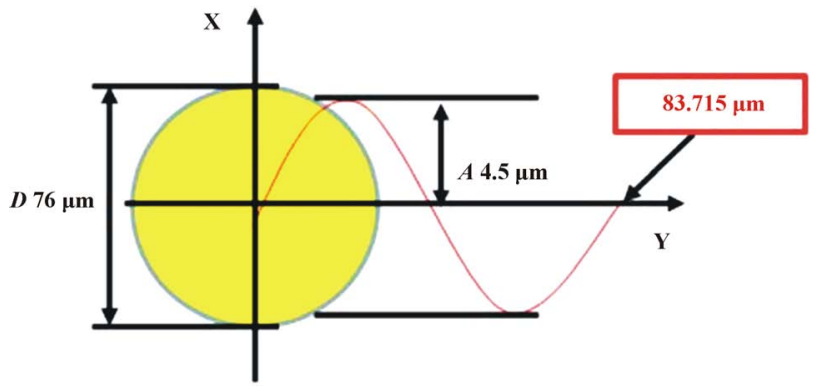

Figure 12. Kinematic of a diamond grain in ultrasonic grinding.

the surface roughness.

The following conclusions can be drawn from the present work:

The optimal sampling rate was selected based on the signal processing and waterfall FFT analysis. Besides, the signal processing method was considered as the grinding force analysis.

In the comparison of conventional and ultrasonic assisted grinding, the forces in ultrasonic assisted machining were lower about $20 \%$ - 30\%. However, the forces in the ultrasonic grinding in y direction were higher than that in the conventional grinding possibly due to deeper depth of cut in the ultrasonic grinding.

From the surface roughness measurement, it can be concluded that ultrasonic assisted machining could reduce the surface roughness by $5 \%-15 \%$. And also it was observed that the surface roughness was improved as the feed rate decreased and the grinding speed increased.

From SEM and AFM measurements, the sinusoidal scoring marks were clearly observed on the machined surface in ultrasonic grinding while the straight marks were observed in the conventional grinding. These sinusoidal waves generated by ultrasonic vibration in longitudinal direction can improve the surface integrity effectively.

\section{Acknowledgements}

This work was supported by the Industrial strategic technology development program, "Development of Nextgeneration Hybrid Grinding System” funded by the Ministry of Trade, Industry \& Energy (MOTIE, Korea).

\section{REFERENCES}

[1] G. Spur and S.-E. Holl, "Ultrasonic Assisted Grinding of Ceramics,” Journal of Materials Processing Technology, 
Vol. 62, No. 4, 996, pp. 287-293.

[2] H. Gong, F. Z. Fang and X. T. Hu, "Kinematic View of Tool Life in Rotary Ultrasonic Side Milling of Hard and Brittle Materials," International Journal of Machine Tools \& Manufacture, Vol. 50, No. 3, 2010, pp. 303-307. http://dx.doi.org/10.1016/j.ijmachtools.2009.12.006

[3] H. G. Wobker and H. K. Tonhoff, "High-Efficiency Grinding of Structural Ceramics," NIST Special Publication, Vol. 847, 1993, pp. 171-183.

[4] J. P. Choi, B. H. Jeon and B. H. Kim, "Chemical-Assisted Ultrasonic Machining of Glass,” Journal of Materials Processing Technology, Vol. 191, No. 1-3, 2007, pp. 153156. http://dx.doi.org/10.1016/j.jmatprotec.2007.03.017

[5] G. F. Gao, B. Zhao, D. H. Xiang and Q. H. Kong, "Research on the Surface Characteristics in Ultrasonic Grinding Nano-Zirconia Ceramics," Journal of Materials Processing Technology, Vol. 209, No. 1, 2009, pp. 32-37. http://dx.doi.org/10.1016/j.jmatprotec.2008.01.061

[6] J. Akbari, H. Borzoie and M. H. Mamduhi, "Study on Ultrasonic Vibration Effects on Grinding Process of Alumina Ceramic $\left(\mathrm{Al}_{2} \mathrm{O}_{3}\right)$," World Academy of Science, Engineering and Technology, Vol. 41, 2008, pp. 785-789.

[7] W. M. Zeng, Z. C. Li, Z. J. Pei and C. Treadwell, “Experimental Observation of Tool Wear in Rotary Ultrasonic Machining of Advanced Ceramics,” International Journal of Machine Tools \& Manufacture, Vol. 45, No. 12-13, 2005, pp. 1468-1473. http://dx.doi.org/10.1016/j.ijmachtools.2005.01.031

[8] T. Tawakoli and B. Azarhoushang, "Ultrasonic Assisted
Dry Grinding of 42CrMo4," The International Journal of Advanced Manufacturing Technology, Vol. 42, No. 9-10, 2009, pp. 883-891. http://dx.doi.org/10.1007/s00170-008-1646-7

[9] R. Singh and J. S. Khamba, "Taguchi Technique for Modeling Material Removal Rate in Ultrasonic Machining of Titanium," Materials Science and Engineering, Vol. A460-461, 2007, pp. 365-369. http://dx.doi.org/10.1016/j.msea.2007.01.093

[10] P. L. Guzzo, A. H. Shinohara and A. A. Raslan, “A Comparative Study on Ultrasonic Machining of Hard and Brittle Materials ," Journal of the Brazilian Society of Mechanical Sciences and Engineering, Vol. XXVI, No. 1, 2004, pp. 56-61.

[11] N. Suzuki, S. Masuda, M. Haritani and E. Shamoto, "Ultraprecision Micromachining of Brittle Materials by Applying Ultrasonic Elliptical Vibration Cutting," Proceedings of the 2004 International Symposium on Micro-Nano Mechatronics and Human Science, 2004, pp. 133-138.

[12] Y. Z. Liu, Y. C. Liang and F. H. Zhang, "Machining Characteristics Analysis of Nano Ceramics in Ultraprecision Grinding Machining,” Key Engineering Materials, Vol. 304, 2006, pp. 210-213. http://dx.doi.org/10.4028/www.scientific.net/KEM.304-3 $\underline{05.210}$

[13] D. H. Xiang, Y. P. Ma, B. Zhao and M. Chen, "Study on Ultrasonic Vibration Grinding Character of Nano $\mathrm{ZrO}_{2}$ Ceramics,” Key Engineering Materials, Vol. 291, 2005, pp. 45-50. 